\title{
Teoria e Prática na Reconstrução da Concepção de Linguagem do Professor de Línguas
}

\author{
Solange T. Ricardo de Castro
}

Universidade de Taubaté

This paper aims at discussing the results of learning opportunities, offered to English state school teachers in the Greater São Paulo, in the reconstruction of their language conceptions. The learning situations these teacher take part in, within a course which has the objective of preparing reflective teachers, are structured to integrate theoretical discussions and practical experiences (Vygotsky, 1987). The focus is on the transformations observed in the teachers' language conceptions, through their instructional choices during the preparation of lesson plans at two particular moments along the four weeks of a module which is part of the course.

Este trabalho tem como objetivo discutir os resultados de oportunidades de aprendizagem, oferecidas a professores de inglês da rede pública estadual, na reconstrução de suas concepções de linguagem. As situações de aprendizagem de que esses professores participam, dentro de um curso que visa a formar professores reflexivos, são estruturadas para integrar discussões teóricas e experienciações práticas (Vygotsky, 1987). Discutem-se as transformações observadas nas concepções de linguagem desses professores, através das escolhas instrucionais que fazem durante o planejamento de aulas, em dois momentos ao longo das quatro semanas de um módulo integrante do curso.

\section{Introdução}

No processo de reconstrução do conhecimento do professor de línguas, devem estar envolvidas (a) a aquisição de conhecimentos teóricos, principalmente sobre a natureza da linguagem em sala de aula e fora dela e sobre os processos de ensinar e aprender línguas (Moita Lopes, 1996) e (b) novas experienciações da prática anterior, transformada (Stake, 1987; Schön, 1988, com base em Dewey, 1933; Celani, 1992). Essas experienciações devem ser acompanhadas de análise e reflexão cuidadosas sobre e durante a própria prática (Garcia, 1992; Schön, 1988; Magalhães, 1998; Castro, 1999).

Neste trabalho, examinamos os resultados das oportunidades de aprendizagem, construídas, durante um módulo de 16 horas-aula, nos moldes acima mencionados, como parte de um curso de formação em serviço para professores de inglês da rede pública estadual da Grande São Paulo. Nesse módulo, ministrado por esta professora-pesquisadora, discussões teóricas e experienciações práticas integraram-se, nas situações de aprendizagem construídas, para promover o repensar das ações instrucionais desses professores, dentro da proposta do curso como um todo. Ao apresentarmos este estudo, pretendemos oferecer subsídios para que programas de formação em serviço e em pré-serviço possam ser implementados. 
A ênfase do trabalho está no exame da reconstrução das escolhas instrucionais dos professores-alunos. Mais especificamente, examinamos as transformações observadas nos planos de aula por eles elaborados, à medida que essas escolhas passaram a refletir uma compreensão da natureza sociointeracional da linguagem (e da aprendizagem) e a contemplar situações de uso da linguagem como prática social. Os dados foram coletados na primeira semana de aulas (Momento 1) e na terceira (Momento 2).

Para atingirmos nossos objetivos, discutimos inicialmente, o processo de reconstrução do conhecimento do professor, dentro da perspectiva vygotskiana (Vygotsky, 1987) e neo-vygotskiana (Bruner, 1983; Gavelek, 1984; Au \& Kawakami, 1984; Rogoff, 1984; Moll, 1991). Após, examinamos as ações instrucionais do módulo ministrado. A seguir, discutimos os resultados encontrados nos trabalhos elaborados pelos professoresalunos, e tecemos algumas considerações finais.

\section{Processo de reconstrução do conhecimento do professor}

Entendida dentro da perspectiva vygotskiana (Vygotsky, 1930/1991), a reconstrução do conhecimento do professor ocorre dentro das relações sociais, em um processo no qual a linguagem do parceiro colaborador (outro professor, o supervisor, o coordenador, o pesquisador, etc.) tem papel crucial. Esse processo envolve a transformação dos sistemas de formas de pensamento do professor, os quais, por sua vez, consistem da superação e reorganização das formas anteriores. Nesse processo, ao se incorporar ao pensamento do aprendiz, o novo significado se estende às formas mais antigas $\mathrm{e}$ as modifica, reorganizando-as em novos sistemas. Essa reorganização das formas de pensamento, por sua vez, dá lugar a novas formas de ação em relação a ou nas situações instrucionais.

A formação dos novos sistemas de pensamento do professor dá-se no decorrer das oportunidades de aprendizagem das quais esse profissional participa, em que a mediação pela palavra (falada ou escrita) tem papel crucial. Nesse processo, o professor revê e compara constantemente experiências/ações de ensino, próprias e de outros, e re-elabora continuadamente seu conhecimento, repensando, modificando ou expandindo seus conceitos de linguagem e de aprendizagem (Schön, 1988; Rogoff, 1984; Gavelek, 1984).

Stake (1987) salienta que a mudança da prática do professor deve ser gradual, "planejada internamente", isto é, adaptada às formas de ser do professor, havendo uma combinação de novas experiências com as antigas. Esse tipo de mudança implica em que o professor (a) tenha mais informações teóricas e as use racionalmente; (b) entenda melhor sua própria prática refletindo sobre os porquês e os comos; (c) no decorrer de sua ação efetue mudanças baseadas no novo conhecimento e em novas experiências (que podem ser vicárias) e que levam a um reexame dos problemas.

Schön (1988) propõe com base em Dewey (1933) a noção do aprender fazendo que é a modificação da prática anterior do professor através de novas experienciações. A nova experiência (vicária ou não) interage com o conhecimento anterior do professor e assim ele experiência no dia a dia novas formas de atuação que vão compor sua transformação. $\mathrm{O}$ novo conhecimento atua sobre as ações subseqüentes e o professor é, então, capaz de transformar as situações problemáticas que encontra, propondo novas soluções para elas ou percebendo novas aplicações para as respostas que ele já conhecia de situações anteriores.

Vygotsky (1987) explica o desenvolvimento de novos conhecimentos à luz da dependência mútua entre os conceitos científicos e os conceitos espontâneos. Para ele, as 
trajetórias dos dois tipos de conhecimentos, a dos conhecimentos adquiridos em situações escolares (conceitos científicos), no caso deste trabalho, as teorias de linguagem e de aprendizagem de línguas, que subjazem aos métodos e abordagens de línguas conhecidos, como veremos mais além, e a dos conhecimentos adquiridos durante experienciações práticas (conceitos espontâneos), influenciam-se mutuamente. Isso possibilita ao professor refinar sua percepção e definição de (novas) formas de atuação e escolhas instrucionais.

\section{Ações Docentes no Módulo}

Para promover oportunidades de aprendizagem aos professores-alunos que integrassem teoria e prática, possibilitamos a eles, durante as aulas (a) a discussão das teorias de linguagem e de aprendizagem de línguas subjacentes aos métodos e abordagens mais tradicionalmente conhecidos (Método da Tradução e Gramática; Método Direto; Método Audiolingual; Abordagem Comunicativa), e (b) a elaboração de planos de aula, tarefa essa realizada em grupos.

As teorias de linguagem e de aprendizagem de línguas foram elicitadas dos professores-alunos e discutidas através da análise de aulas características de cada método ou abordagem. A análise (v. Larsen Freeman, 1986) foi feita com base nas ações instrucionais características de cada método ou abordagem, nos objetivos instrucionais dessas ações, nos papéis de alunos e professores nas interações de sala de aula, na natureza das interações verificadas, bem como em outros aspectos relevantes, como por exemplo, na maneira de correção de erros ou na escolha da língua usada durante as aulas, materna ou língua alvo.

É importante salientar que, nesse processo, os professores trouxeram para a discussão elementos de suas próprias aulas, fossem ações instrucionais escolhidas, tópicos tematizados ou modos de participação dos alunos. É também importante salientar que, nesse processo ainda, as ações discursivas da docente-pesquisadora enfatizaram o significado e a relevância das ações e teorias examinadas em cada método ou abordagem, dentro de seus momentos históricos, como a "verdade" conhecida naquele ou até aquele momento, contrapondo-as à visão sociointeracional de linguagem e de aprendizagem (Parâmetros Curriculares Nacionais - Língua Estrangeira), e ao exame das necessidades das salas de aula de hoje.

Questões típicas colocadas pela professora-pesquisadora foram, então, "Que tipos de alunos estamos querendo formar?", "De que os alunos precisam para conseguir se inserir na sociedade de hoje e participar ativamente?", "Que tipos de capacidades precisam desenvolver?", "Se estamos educando um aluno só para repetir o que dizemos ou só para aplicar as regras que ensinamos, que tipos de competências estamos construindo com esses alunos?"

Os planos de aula, por sua vez, foram elaborados pelos professores-alunos em grupos, na primeira semana de aulas, a partir dos objetivos de ensino (Celani, 1984, 1987/1995, 1992; Costa, 1987) para situações de ensino fundamental e médio, discutidos e definidos como parte do trabalho do módulo anterior. Na terceira semana de aulas, esses planos foram retomados pelos professores-alunos e re-elaborados à luz das discussões teórico-práticas do módulo em andamento.

É importante salientar ainda que, ao longo das ações docentes do módulo, as escolhas discursivas da professora-pesquisadora salientaram também os porquês dessas 
ações, tanto em relação aos objetivos do próprio módulo, a saber, a aprendizagem de teorias de aprendizagem de línguas e de linguagem, como em relação às ações de outros módulos e ao objetivo do curso como um todo, a saber, o de formar um professor reflexivo.

\section{Concepções de Linguagem}

Os resultados observados quanto às concepções de linguagem subjacentes às escolhas instrucionais dos professores-alunos, nos planos de aula re-elaborados na terceira semana de aulas do módulo, parecem indicar que, nesse momento, as ações dos professores-alunos começam a se embasar em uma visão sociointeracional de linguagem, e não em visões mais tradicionais, como as que subjazem às escolhas feitas na primeira semana. Ou seja, as escolhas dos professores-alunos nesse momento, parecem sugerir uma tentativa de construção de linguagem com os alunos, como uma prática centrada naquilo que é dito/ escrito, para um determinado ouvinte/leitor, dentro de uma determinada situação social. Para ilustrarmos o que acabamos de afirmar, apresentamos no quadro mais adiante (Concepções de linguagem dos professores-alunos), e examinamos, as escolhas instrucionais características de cada um dos dois momentos de três professores-alunos.

Como pode ser visto no quadro, através das escolhas dos professores-alunos, as ações instrucionais contempladas nos planos de aulas do Momento 1 apóiam-se principalmente em uma visão estrutural de linguagem (professor-aluno 3, por exemplo), ou em uma visão funcional (professor-aluno 1, por exemplo). Nesse momento, essas ações parecem ainda se embasar em uma visão de que a linguagem é um conjunto de hábitos, que deverão ser aprendidos através da prática dos conhecimentos transmitidos, isto é, repetição de elementos ou blocos de elementos lingüísticos e/ou aplicação de conhecimentos gramaticais.

\section{Quadro: Concepções de linguagem dos professores}

Momento 1: linguagem como um sistema de Momento 2: linguagem marcada pelo mundo estruturas; como um conjunto de hábitos; ou social que a envolve; construção dialógica como um veículo para a expressão do significado funcional da linguagem

\section{Professor-aluno 1}

Interação aluno/aluno e aluno/professor.

Verificar com os alunos os seus conhecimentos sobre greetings. Depois, os alunos interagem com outros alunos, aplicando o que foi aprendido sobre greetings.
Perguntar aos alunos como cumprimentam em português e anotar na lousa. Depois, pedir que eles me digam como cumprimentam um professor ou diretor e anotar na lousa. Após, alunos discutem as diferenças entre as linguagens/expressões utilizadas. Fazer a mesma coisa em inglês. 


\begin{tabular}{|c|c|}
\hline \multicolumn{2}{|c|}{ Professor-aluno 2} \\
\hline $\begin{array}{l}\text { Apresentar o contexto (situações). Ao che- } \\
\text { gar á sala, o professor os cumprimenta em } \\
\text { inglês, e fala sobre as formas formais e } \\
\text { informais dos cumprimentos. Lista vocabu- } \\
\text { lário conhecido. Introduz novas palavras, de } \\
\text { interesse para desenvolvimento das aulas. } \\
\text { Oralmente, apresenta o vocabulário e os } \\
\text { alunos repetem. O professor faz o texto com } \\
\text { um aluno. Diálogo em dupla. Divide a sala } \\
\text { em dois grupos: A e B. Fazem o diálogo } \\
\text { (grupão). Duplas - dividir em duplas A e B. } \\
\text { Os alunos reproduzem o diálogo oralmente } \\
\text { sem ler. No final da aula, lêem o texto e } \\
\text { reproduzem o mesmo em seus cadernos. }\end{array}$ & $\begin{array}{l}\text { Fazer o levantamento das várias situações } \\
\text { formais e informais, nas quais os participan- } \\
\text { tes se apresentam. Formular perguntas: co- } \\
\text { mo você deve se comportar, e cumprimen- } \\
\text { tar diante de determinadas situações, ex: } \\
\text { aniversário em família, escola, igreja, en- } \\
\text { contro de amigos. Analisar um diálogo de } \\
\text { uma determinada situação: recreio. Fazer } \\
\text { perguntas sobre a ilustração. Perguntas so- } \\
\text { bre onde acontece o diálogo: quem partici- } \\
\text { pa? Onde estão? De que falam? O que fa- } \\
\text { lam? O que fazem? Quais palavras conhe- } \\
\text { cem do texto? O professor trabalha a } \\
\text { pronúncia e depois aluno com aluno. }\end{array}$ \\
\hline \multicolumn{2}{|c|}{ Professor-aluno 3} \\
\hline $\begin{array}{l}\text { Mostrar trechos de cartas. O aluno vai } \\
\text { comparar as cartas para identificar as } \\
\text { mesmas. O aluno vai reconhecer o lay-out } \\
\text { em grupo ou pair-work. Identificar os } \\
\text { tópicos de cada item. Sistêmico: trabalhar } \\
\text { com cognatos; likes and dislikes; verb } \\
\text { tenses; adjectives. Ao final os alunos } \\
\text { deverão ela-borar uma carta, após discutir } \\
\text { entre eles o tema da carta. }\end{array}$ & $\begin{array}{l}\text { Após ter mostrado uma carta, pedir para os } \\
\text { alunos observarem o lay-out, apresentação } \\
\text { textual da carta, o endereçamento e a des- } \\
\text { pedida. Em seguida, mostrar outra carta, } \\
\text { comparando as duas. Pedir para os alunos } \\
\text { elencarem as diferenças, por exemplo: for- } \\
\text { ma de tratamento, como é usado o vocabu- } \\
\text { lário, o endereçamento e a despedida. Falar } \\
\text { um pouco sobre contracted forms, e pedir } \\
\text { para os alunos relacionarem algumas delas e } \\
\text { observarem se na carta mais formal há ou } \\
\text { não esse tipo de construção. Pedir para eles } \\
\text { darem uma explicação do porquê de não usar } \\
\text { este tipo de tratamento em uma carta formal. }\end{array}$ \\
\hline
\end{tabular}

Antes de passarmos aos exemplos, esclareçamos um pouco essas visões. A primeira, a visão funcional, entende a linguagem "como um veículo para a expressão do significado funcional" (Richards \& Rodgers, 1986:16), e especifica e organiza o conteúdo do ensino em termos de categorias de significado e função e não por elementos de estrutura e gramática, como na visão estrutural, que veremos a seguir. Nesse sentido, segundo Richards \& Rodgers, um programa funcional inclui não apenas elementos de gramática e léxico, mas também especifica os tópicos, noções, e conceitos que o aprendiz precisa aprender para se comunicar.

A segunda, a visão estrutural, entende a linguagem como "um sistema de elementos estruturalmente relacionados para codificar o significado" (Richards e Rodgers, 1986:16). Nessa visão, o objetivo do aprendizado de línguas é o domínio dos elementos desse sistema, que são geralmente definidos em termos de unidades fonológicas (por exemplo, fonemas), unidades gramaticais (por exemplo, orações, frases, sentenças), operações 
gramaticais (por exemplo, acrescentar, trocar, combinar, ou transformar elementos), e itens lexicais (por exemplo, palavras de conteúdo).

Associadas a teorias de aprendizagem, por sua vez, essas visões podem ainda dar origem a outras concepções de linguagem (Richards e Rodgers, 1986:19). Por exemplo, associadas ao behaviorismo, essas visões podem originar uma concepção de linguagem como um conjunto de hábitos (lingüísticos), a serem adquiridos através de repetição, de memorização, e/ou de aplicação de regras. Ou, associadas ao cognitivismo, essas visões podem originar uma concepção de linguagem como comunicação, a ser adquirida através da aplicação/uso em situações reais, de conhecimento transmitido pelo professor.

No caso deste trabalho, como dissemos anteriormente, a visão estruturalista e a visão funcional podem ser encontradas embasando algumas escolhas de conteúdos do professor-aluno 3, por exemplo, verb tenses ou adjectives, no primeiro caso (visão estruturalista), ou dos professores-alunos 1 e 3, por exemplo, greetings, e likes and dislikes, no segundo caso (visão funcional).

Mais além, a concepção de língua como um conjunto de elementos que precisam ser praticados ou memorizados para serem adquiridos, por outro lado, aparece também nas escolhas desses professores, como, por exemplo, em aplicando o que foi aprendido sobre greetings (professor-aluno 1), ou [o professor] apresenta o vocabulário e os alunos repetem (professor-aluno 2). Também, a visão de língua como um conhecimento a ser ensinado/transmitido pelo professor, para o aluno, que vai depois aplicá-lo em situações de comunicação, pode ser vista em várias ações do professor-aluno 2, como por exemplo, em [o professor] fala sobre as formas formais e informais dos cumprimentos, lista vocabulário conhecido, introduz novas palavras de interesse para o desenvolvimento das aulas, oralmente apresenta o vocabulário, e, posteriormente, faz o texto com um aluno, e os alunos fazem o diálogo em dupla, entre outros.

$\mathrm{O}$ fato de que as ações instrucionais desses professores-alunos começam a se apoiar em outras concepções de linguagem que não aquelas mais tradicionalmente observadas, no entanto, pode ser visto através das escolhas feitas quando da re-elaboração dos planos de aula, no Momento 2 do estudo. As ações observadas nesse momento parecem enfatizar tentativas de construir com os alunos uma visão de que as situações interacionais são marcadas pelo mundo social que os envolve (Parâmetros Curriculares Nacionais - Língua Estrangeira: 27).

Como pode ser visto no quadro, os professores-alunos constroem situações em que os alunos pensam em como cumprimentam um professor ou diretor (professor-aluno 1), em que os professores-alunos pensam em situações formais e informais, nas quais os participantes se apresentam (professor-aluno 2), em que formulam perguntas sobre como o aluno deve se comportar e cumprimentar diante de determinadas situações, como, por exemplo, um aniversário em família, etc. (professor-aluno 2), em que levam os alunos a elencarem diferenças de tratamento em uma carta (professor-aluno 3), ou em que levam os alunos a enfocarem as situações nas quais o diálogo acontece através de perguntas, como quem participa, onde estão, e outras (professor-aluno 2).

$\mathrm{O}$ fato de que a linguagem começa a ser entendida em sua função dialógica, isto é, como tendo os significados construídos pelos participantes do discurso em sala de aula, também parece ser o caso nesse momento. Assim, por exemplo, as ações dos professores sugerem a participação e o envolvimento mais ativos do aluno na construção do novo conhecimento, o que pode ser visto através de perguntar aos alunos como cumprimentam, no caso do professor-aluno 1, por exemplo. Da mesma forma, ainda, as ações atribuídas aos 
alunos sugerem essa participação, como em alunos discutem as diferenças entre as linguagens/ expressões utilizadas, como no caso do professor-aluno 1 , ou pedir aos alunos para darem uma explicação do porquê de não usar um tipo de tratamento mais informal em uma carta formal, como no caso do professor-aluno 3. Ou seja, essas escolhas dos professores-alunos, nesse momento apontam um movimento do professor em direção a uma visão sociointeracional de linguagem que, segundo Moita Lopes (1999:19), "se baseia no princípio de que, ao se engajarem no discurso, as pessoas levam em consideração aqueles envolvidos na interação, seus interlocutores - tanto a quem se dirige quanto a quem se dirigiu a elas - no ato da construção social do significado escrito ou oral."

\section{Considerações Finais}

Neste trabalho, propusemo-nos a discutir os resultados observados na reconstrução da concepção de linguagem de um grupo de professores de inglês, a partir de um trabalho em sala de aula que envolveu discussões de teorias e experienciações práticas. Esses resultados indicam a emergência de novas concepções de linguagem presentes nas ações dos professores-alunos envolvidos no estudo, o que significa que o arcabouço teóricoprático apresentado merece investigações adicionais.

Perguntas que poderiam ser exploradas futuramente visando a uma melhor compreensão do processo poderiam envolver, por exemplo, a caracterização da linguagem do mediador (professor ou colega) durante as interações, à medida que os professores alunos replanejam suas ações. Outras poderiam envolver, ainda, a caracterização das ações docentes desses professores-alunos durante as aulas que ministram, ao longo de sua participação em cursos de formação - apresentam essas aulas índices de transformação que corroboram os resultados observados durante o planejamento?

A compreensão dessas e de outras questões coloca-se como essencial para que processos de formação em serviço (e em pré-serviço) possam ser implementados.

\section{Referências bibliográficas}

AU, K. H.; KAWAKAMI, A . J. Vygotskian perspectives on discussion processes in small-group reading lessons. In: PETERSON, P. L.; WILKINSON, L.; HALLINAN, M. The social context of instruction. Orlando: Academic Press, 1984. p. 209-225.

BRASIL. Ministério da Educação. Parâmetros Curriculares Nacionais. Língua Estrangeira/Terceiro e quarto ciclos da escola fundamental, 1998.

BRUNER, J. Child's talk: learning to use language. Oxford: Oxford University Press, 1983.

CASTRO, S. T. R. Teoria e Prática na Construção da Concepção de Linguagem como Prática Social na Formação Continuada do Professor. In: DUTRA, D.; MELLO, H. R.; PAIVA, V. L. M. O. (Orgs.): CONGRESSO BRASILEIRO DE LINGÜÍSTICA APLICADA, 6., 2001, Belo Horizonte, Programa e Resumos, Belo Horizonte, Associa;áo de Lingüística Aplicada do Brasil, 2001, p. 233, 2001. 
CASTRO, S. T. R.. A linguagem e o processo de construção do conhecimento: Subsídios para a formação do professor de inglês. 1999. 239 f. Tese (Doutorado em Lingüística Aplicada ao Ensino de Línguas e Estudos da Linguagem) - Pontifícia Universidade Católica, São Paulo.

CELANI, M. A. A. Uma abordagem centrada no aluno para os cursos de Letras. In: CELANI, M. A. A. (Ed.) Ensino de Línguas. São Paulo: EDUC, p. 32-39, 1984.

CELANI, M. A. A. (1987). As línguas estrangeiras e a ideologia subjacente à organização dos currículos da escola pública. In: Educação para crescer. Rio Grande do Sul: Secretaria da Educação, 1995. p. 23-29.

CELANI, M. A. A. Providing opportunities for learning: Teacher training experience. In: ESSEN; BURKART (Ed.). Homage to W. R. Lee. Berlin/New York: Foris Publications, 1992. p. 29-37.

COSTA, D. N. M. Por que ensinar língua estrangeira na escola de $1^{\circ}$ grau. São Paulo: EDUC, 1987.

DEWEY, J. (1933). John Dewey on education: Selected writings. Chicago: University of Chicago Press, 1979.

GARCIA, C. M. A formação de professores: Novas perspectivas baseadas na investigação sobre o pensamento do professor. In: NÓVOA, A. (Org.) Os professores e sua formação. Lisboa: Publicações Dom Quixote, 1992. p. 53-76.

GAVELEK, J. R. The social contexts of literacy and schooling: a developmental perspective. In: TAFFY, E. (Ed.) The contexts of school-based literacy. New York: Random House, p. 3-25, 1984.

LARSEN FREEMAN, D. Techniques and principles in language teaching. Oxford: Oxford University Press, 1986.

MAGALHÃES, M. C. C. Projetos de formação contínua de educadores para uma prática crítica. The ESPecialist, São Paulo, v. 19, p. 169-184, 1998.

MOITA LOPES, L. P. A contribuição da Lingüística Aplicada na formulação dos Parâmetros Curriculares Nacionais de Língua Estrangeira: A questão dos temas transversais. Intercâmbio, São Paulo, v. VIII, p. 17-24, 1999.

MOITA LOPES, L. P. Oficina de Lingüística Aplicada. Campinas: Mercado de Letras, 1996.

MOLL, L. C. Teaching second language students: a vygotskian perspective. In: JOHNSON, Donna M.; ROEN, Duane H. (Ed.) Richness in writing: empowering ESL students. NY: Longman, 1991. p.55-69. 
RICHARDS, J.C.; RODGERS, T.S. Approaches and Methods in Language Teaching. Cambridge: Cambridge University Press, 1986.

ROGOFF, B. Adult assistance of children's learning. In: TAFFY, E. (Ed.) The contexts of school-based literacy. New York: Random House, 1984. p. 27-40.

SCHÖN, D. Educating the reflective practitioner. San Francisco: Jossey-Bass, 1988.

STAKE, R. E. An evolutionary view of programming staff development. In: WIDEEN, M.; ANDREWS, I. (Ed.) Staff development for school improvement. Philadelphia: The Palmer Press, 1987. p. 55-69.

VYGOTSKY, L. (1930) Sobre los sistemas psicologicos. In: VYGOTSKI, L. (1982) Obras Escogidas. Madrid: Aprendizage/Visor, v. 1, 1991.

VYGOTSKY, L. Pensamento e linguagem. SP: Martins Fontes, 1987. 